\title{
Sexual maturation in male rhesus monkeys: importance of neonatal testosterone exposure and social rank
}

\author{
D R Mann, M A Akinbami, K G Gould ${ }^{1}$, K Paul ${ }^{\mathbf{1}}$ and K Wallen $^{\mathbf{1}}$ \\ Department of Physiology, Morehouse School of Medicine; ${ }^{1}$ Department of Psychology, Emory University and Yerkes Regional Primate Research Center, \\ Atlanta, Georgia, USA \\ (Requests for offprints should be addressed to D R Mann, Department of Physiology, Morehouse School of Medicine, 720 Westview Dr. SW, Atlanta, \\ Georgia 30310-1495, USA)
}

\begin{abstract}
In a 5-year longitudinal study, we examined the effect of disrupting the neonatal activity of the pituitary-testicular axis on the sexual development of male rhesus monkeys. Animals in a social group under natural lighting conditions were treated with a GnRH antagonist (antide), antide and androgen, or both vehicles, from birth until 4 months of age. In antide-treated neonates, serum LH and testosterone were near or below the limits of detection throughout the neonatal period. Antide+androgen-treated neonates had subnormal serum LH, but above normal testosterone concentrations during the treatment period. From 6 to 36 months of age, serum LH and testosterone were near or below the limits of detection. Ten of 12 control animals reached puberty during the breeding season of their 4th year, compared with five of 10 antide- and three of eight antide+androgen-treated animals. Although matriline rank was balanced across treatment groups at birth, a disruption within the social group during year 2 resulted in a marginally lower social ranking of the two treated groups compared with the controls. More high (78\%) than low
\end{abstract}

(22\%) ranking animals reached puberty during year 4 . During the breeding season of that year, serum $\mathrm{LH}$, testosterone and testicular volume were positively correlated with social rank. Thus the lower social rank of treated animals may have contributed to the subnormal numbers of these animals reaching puberty during year 4 . However, of those animals achieving puberty during year 4 , the pattern of peripubertal changes in serum testosterone and testicular volume differed between control and antidetreated animals. The results appear to suggest that the disruption of normal activity of the neonatal pituitarytesticular axis retarded sexual development, but that social rank is a key regulatory factor in setting the timing of sexual maturation in male rhesus monkeys. The effect of neonatal treatment with antide and low social rank on sexual development could not be reversed by neonatal exposure to greater than normal concentrations of androgen.

Journal of Endocrinology (1998) 156, 493-501

\section{Introduction}

The hypothalamic-pituitary-testicular axis of male primates is transiently activated for the first 4-6 months of postnatal life, and then activity of this axis declines to low basal levels characteristic of the juvenile period (Mann et al. 1984, 1989, Forest 1990, Lunn et al. 1994, Plant 1994). With the reinitiation of pulsatile secretion of gonadotropin releasing hormone $(\mathrm{GnRH})$ during the late prepubertal period, the increase in gonadotropin secretion leads to enlargement of the testes and the initiation of spermatogenesis. In the rhesus monkey, a seasonal breeder when maintained under natural environmental conditions, the onset of puberty usually occurs during the breeding season of year 4, otherwise, it is delayed until the subsequent breeding season (Mann et al. 1993). The possible importance of neonatal endocrine events in regulating the timing of pubertal changes and the achievement of the full reproductive potential of the male primate have not been fully investigated. In several non-primate species, neonatal brain-pituitary-testicular activity has a role in the masculinization of the central nervous system, determination of Sertoli cell number, maturation of feedback systems regulating gonadotrophin secretion, development of the immune system, and social and sexual behavior (Goy \& McEwen 1980, Huhtaniemi et al. 1986, 1989, Kolho \& Huhtaniemi 1989, Baum et al. 1990, van den Dungen et al. 1990, Mann \& Fraser 1996). In primates, neonatal events have been found to influence the timing of puberty and peripubertal and adult gonadotropin and testosterone secretion (Mann et al. 1989, 1993, Lunn et al. 1994). It is important to understand the significance of this period for the development of the hypothalamic-pituitary-testes axis, as the frequency of reproductive disorders in boys and men has increased over the past 50 years (Sharpe 1993, 1994). There is also concern that perinatal events such as 
caesarean section or premature delivery could alter neonatal endocrine events, potentially affecting reproductive maturation and adult sexual function (Mann \& Fraser 1996).

In a previous study, we chronically administered (from 10-13 days to 4 months of age) a GnRH agonist (GnRH-A) to rhesus monkeys, to examine the effect on their sexual development of reversibly suppressing neonatal pituitary-testicular function (Mann et al. 1984, 1989, Eisler et al. 1993). Treated animals had either an attenuated pubertal increase in secretion of luteinizing hormone $(\mathrm{LH})$ and testosterone and testicular enlargement during year 4 , or puberty was delayed for 1 year (Mann et al. 1989, 1993). As adults, they had reduced basal LH and testosterone secretion, and retarded skeletal growth and development (Eisler et al. 1993, Mann et al. 1993). Thus the disruption of normal neonatal neuroendocrine events was associated with an altered pattern of sexual maturation and adult pituitary-testicular function.

This initial study raised several issues. First, the use of a $\mathrm{GnRH}-\mathrm{A}$ raised concerns about the potential confounding effect of the initial flare or stimulatory phase of administration of the analog (Filicori \& Flamigni 1988, Friedman 1990). Secondly, GnRH-A treatment was begun on postnatal day 10 and treated animals may thus potentially have been exposed to the characteristically high concentrations of neonatal testosterone for the first 1.5 weeks of postnatal life. Thirdly, the study did not distinguish between the effects of subnormal concentrations of testosterone and possible direct effects of the GnRH-A on sexual development. There was also a need to confirm the results in a larger experimental population.

In the current study, we investigated further the importance of neonatal activation of the hypothalamicpituitary-testicular axis on sexual maturation in male rhesus monkeys. Neonates were treated with a GnRHantagonist (to eliminate the flare phenomenon in GnRHA-treated animals) beginning earlier in the postnatal period (0-2 days of age), and were followed longitudinally to 5 years of age. We also examined whether concurrent androgen replacement would normalize the process of sexual development in GnRH-antagonist-treated neonates. Serendipitous observations confirmed that social rank has an important influence on sexual maturation in male rhesus monkey.

\section{Materials and Methods}

\section{Treatment}

Neonatal male rhesus monkeys (Macaca mulatta) were treated with either vehicle (propylene glycol : water, $1: 1$; $\mathrm{n}=12$ ), a GnRH antagonist (antide; Ac-D-2-Nal ${ }^{1}-\mathrm{D}-4-$ Cl-Phe ${ }^{2}-\mathrm{D}-3-\mathrm{Pal}^{3}-\mathrm{Nic}-\mathrm{Lys}^{5}-\mathrm{D}-\mathrm{Nic}-\mathrm{Lys}^{6}-\mathrm{I}-\mathrm{Lys}^{8}-\mathrm{D}-\mathrm{Ala}^{10}{ }^{10}$ $\mathrm{GnRH} ; 15 \mathrm{mg} / \mathrm{kg}$ body weight by weekly s.c. injection; $\mathrm{n}=10$ ), or antide and androgen (testosterone-trans- $4 \mathrm{n}$ - butylcyclohexancarboxylate; $8 \mathrm{mg} / \mathrm{kg}$ body weight, i.m., every other week for 6 weeks; $n=8$ ) from $0-2$ days of age until 4 months of age. While androgen injections were terminated at 6 weeks, testosterone concentrations in antide + androgen-treated animals were increased above those in controls and antide-treated animals until 4 months of age. Animals were reared with their mothers within either of two social groups (75 and 83 animals/group) in large outdoor compounds $(30 \times 30 \mathrm{~m})$ with attached indoor areas.

\section{Blood sampling and response to $\mathrm{GnRH}$}

Blood samples $(1 \mathrm{ml})$ were drawn between 0800 and $1200 \mathrm{~h}$ by venepuncture from unanesthetized neonates before treatment and weekly thereafter for the remainder of the treatment period. At 4 months of age, the blood sampling frequency was reduced to semi-monthly.

Animals were given an i.v. bolus of GnRH $(50 \mathrm{ng} / \mathrm{kg}$ body weight) at 2 and 6 months of age under ketamine anesthesia (15-20 $\mathrm{mg} / \mathrm{kg}$ body weight), and blood samples $(1 \mathrm{ml})$ were drawn before and at $60 \mathrm{~min}$ after $\mathrm{GnRH}$ administration. Serum was stored at $-70{ }^{\circ} \mathrm{C}$ until required for assay for $\mathrm{LH}$ and testosterone.

\section{Assessment of somatic development, testicular volume, penile length and electroejaculation}

Animals were weighed weekly during the treatment and monthly thereafter. Testicular volume was determined monthly beginning at 2 years of age (Mann et al. 1985). During the breeding season of year 4, after testicular volume reached $5 \mathrm{ml}$, animals were subjected monthly to electroejaculation (under ketamine immobilization) (Gould et al. 1978). At regular intervals, penile length was obtained as a measure of the level of androgenization, by gently stretching the penis and measuring from the tip of the glans to the opening of the foreskin (Wallen et al. 1995).

\section{LH and testosterone assays}

Serum LH was determined using the mouse interstitialcell-testosterone bioassay, as modified by Steiner \& Bremner (1981). Data are expressed in terms of the monkey pituitary WP-XV-20 LH standard. Serum testosterone was measured by RIA using a commercial kit (Diagnostic Products Corporation, Los Angeles, CA, USA). Minimal detectable concentrations of $\mathrm{LH}$ and testosterone were $4 \mathrm{ng} / \mathrm{ml}$ and $0 \cdot 2 \mathrm{ng} / \mathrm{ml}$ respectively.

\section{Social rank}

Rhesus monkey social groups are organized around one or more matrilines. In groups with multiple matrilines, a dominance relationship develops between members 
of matrilines. This allows the construction of a linear dominance hierarchy (Sade 1967). During early development, infants do not have a social rank independent of their mother's rank. Because social rank affects sexual maturation in the male rhesus monkey (Rose et al. 1978, Bercovitch 1993, Bercovitch \& Clarke 1995, Dixson \& Nevison 1997), we balanced social rank across treatment groups.

\section{Statistical analyses}

Data are presented as the mean \pm S.E.M. In neonates, basal LH and testosterone data were analyzed by ANOVA (treatment [control versus antide versus antide + androgen $] \times$ age $[0$ versus 2 versus 6 months of age]) with repeated measures. Body weight data of neonates were analyzed by ANOVA (treatment $\times$ age [0-6 months of age]). Body weight was not corrected for birth weight, because birth weight did not differ across groups. GnRH challenge data at 2 and 6 months of age were analyzed separately by repeated measure ANOVA (treatment $\times$ time after GnRH injection $[0$ versus $60 \mathrm{~min}])$. Peripubertal changes in $\mathrm{LH}$, testosterone, penile length and testicular volume during year 4 were analyzed by repeated measure ANOVA (treatment $\times$ age). Sperm counts across treatment groups (count was average for each animal during the breeding season of year 4) were analyzed by one-way ANOVA. When appropriate, multiple comparisons were performed with Tukey's test. Because all animals were born within a short birth season (approximately 3 months), and as there was no correlation between birthday and age of puberty (breeding season of year 4 or $5)$, the birthday of all animals was normalized to April during year 3 . The effect of treatment on the number of animals achieving sexual maturity during year 4 was assessed using $\chi^{2}$ analysis. Animals were considered to be mature if they exhibited a pubertal increase in testicular size, serum LH and testosterone, or sperm was recoverable upon electroejaculation. Matriline rank at puberty was correlated with peripubertal changes in serum LH, testosterone, testicular volume and body weight using Pearson's correlation test.

\section{Results}

Neonatal changes in body weight, serum LH and testosterone: effect of antide or antide+androgen treatment

Serum LH and testosterone were increased in control animals over the first 2 months of the postnatal period (Fig. 1; published in part previously, Mann et al. 1994). By 6 months of age, LH and testosterone had declined in controls to minimal concentrations of detection. The concentrations of $\mathrm{LH}$ and testosterone remained low from 6 months until 3 years of age. In antide-treated animals,

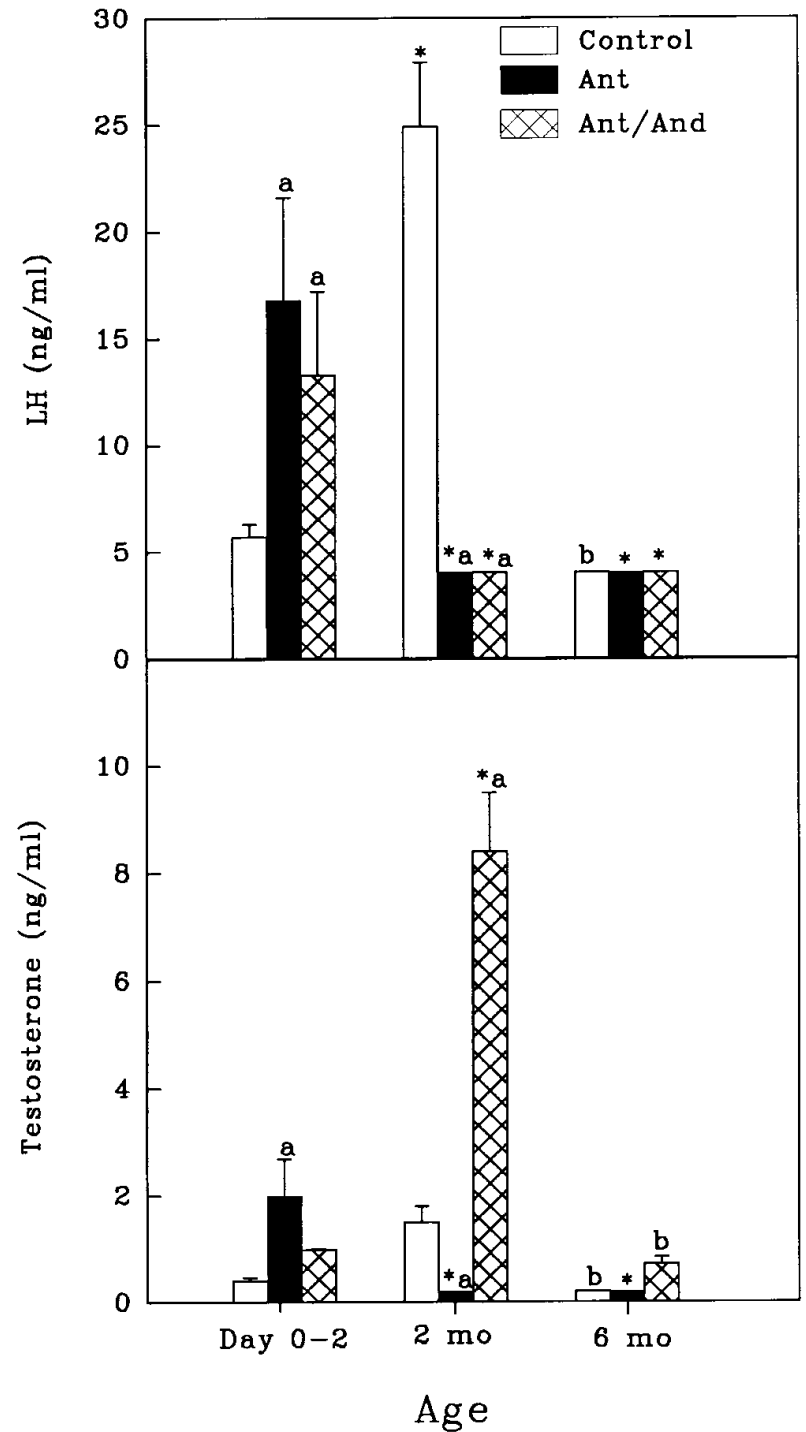

Figure 1 Serum $\mathrm{LH}$ (top) and testosterone (bottom) concentrations at $0-2$ days of age, and 2 months (mo) and 6 months of age in control, antide (Ant)- and antide+androgen (Ant/And)-treated infants. The values at 2 months of age represent the peak values achieved during the first 2 months of life. Values are mean +S.E.M. *Significantly different from the corresponding values at $0-2$ days; ${ }^{\mathrm{a}}$ significantly different from the corresponding control value;

${ }^{b}$ significantly different from the corresponding 2 months value.

serum $\mathrm{LH}$ and testosterone concentrations decreased to detection limits by 1 and 2 weeks of the treatment period respectively, and remained so throughout the treatment period. Antide + androgen-treated animals showed a pattern of decline in serum LH similar to that of antidetreated monkeys. However, serum testosterone in antide+androgen-treated animals increased from a pretreatment value of $1 \cdot 0 \pm 0 \cdot 2$ to $8 \cdot 7 \pm 1 \cdot 0 \mathrm{ng} / \mathrm{ml}$ at 7 weeks of age, but then declined to $0 \cdot 7 \pm 0 \cdot 1 \mathrm{ng} / \mathrm{ml}$ by 6 months of age. 


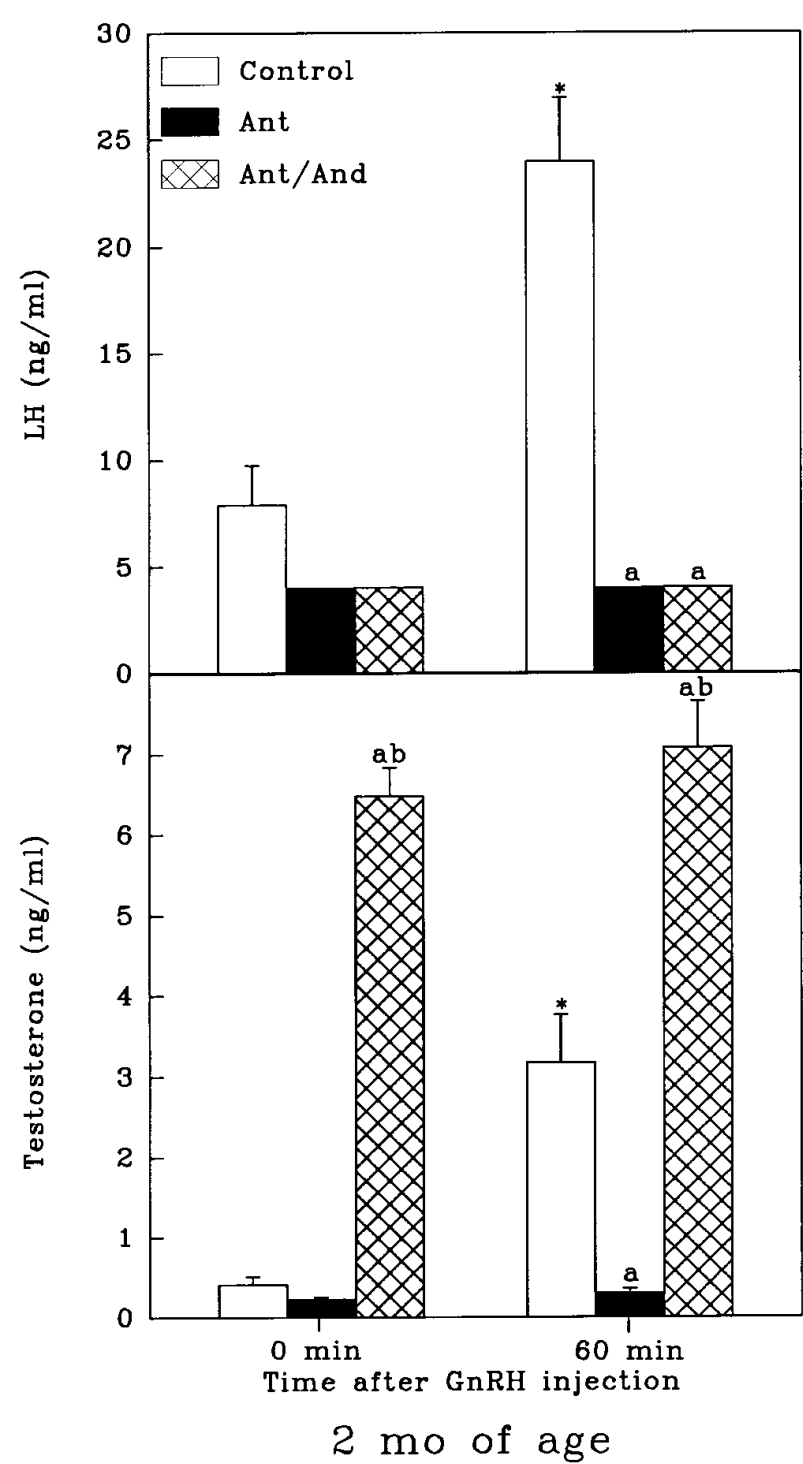

Figure 2 Serum LH (top) and testosterone (bottom) concentrations before and $60 \mathrm{~min}$ after i.v. administration of $50 \mathrm{ng} / \mathrm{kg}$ body weight of $\mathrm{GnRH}$ to 2-month (mo)-old control, antide (Ant)- and antide + androgen (Ant/And)-treated animals. Values are mean + S.E.M. * Significantly different from the corresponding 0-min value; ${ }^{a}$ significantly different from the corresponding control value; ${ }^{b}$ significantly different from the corresponding antide value.

At 2 months of age, controls exhibited a robust serum $\mathrm{LH}$ and testosterone response to GnRH (Fig. 2). By 6 months of age, this response had declined to a minimum in controls (data not shown). Neither antide- nor antide + androgen-treated animals showed a significant $\mathrm{LH}$ or testosterone response to GnRH at 2 or 6 months of age.

Neither antide nor antide+androgen treatment had a significant effect on body weight $(P=0.897$ for treatment effect; $P<0.0001$ for age effect; $P=1.000$ for interaction of the two variables) over the first 6 months of postnatal life (data not shown). Body weight increased in control and treated animals over the first 6 months of life.

Pubertal changes in body weight, penile size, testicular volume, serum LH and testosterone: effect of neonatal treatment with antide or antide+androgen

A larger number (10 of 12) of controls than of antide- (five of $10 ; P<0.03$ ) or antide + androgen-treated (three of eight; $P<0.02)$ animals achieved sexual maturity during the breeding season (October to January) of year 4. Those males in which puberty was delayed became sexually mature during the subsequent breeding season.

Peripubertal serum LH, testosterone and testicular volume data were partitioned within treatment groups into those that did and those that did not reach puberty during year 4 , otherwise data would have been skewed by the larger number of controls reaching puberty. Data were analyzed in two ways: initially treating antide- and antide + androgen-treated animals as separate groups, then collapsing the data across these two groups to assess the effect of antide independent of androgen treatment. Regardless of the approach, there was an effect of age $(P<0 \cdot 0001)$, but no effect of treatment or interaction of treatment and age on LH concentrations (Fig. 3, top). In those animals (regardless of treatment) in which puberty was delayed, LH concentrations remained low throughout this period (data not shown).

When antide- and antide + androgen-treated animals were analyzed as separate entities, there was only an effect of age $(P<0 \cdot 0001)$ on serum testosterone (Fig. 3, middle), but when testosterone data for antide- and antide + androgen-treated animals were combined, there was an interaction of age and treatment $(P=0 \cdot 041)$ on testosterone values (data not shown). Thus, while there was no overall effect of treatment on testosterone concentrations, testosterone values in controls and treated animals varied differently with age. In all animals in which puberty was delayed, serum testosterone remained low during year 4 (data not shown).

Testicular volume increased with age $(P<0 \cdot 0001)$ during year 4 in all animals, but the increase was much greater in those that reached puberty than in those in which puberty was delayed $(P<0 \cdot 0001$; Fig. 3 , bottom). The pubertal increase in testicular volume coincided with the onset of the breeding season, reached a peak in November or December, and then declined as sexual activity slowed. Although there was no overall effect of treatment, there was a significant interaction of treatment and age $(P=0.036)$ on testicular volume in pubertal animals during year 4 , but only when data from antide- and antide + androgen-treated animals were combined in the analysis.

At the beginning of the breeding season (October), body weights of pubertal animals (regardless of treatment) were significantly greater $(6.06 \pm 0.13 \mathrm{~kg} ; \quad P=0.0004)$ 


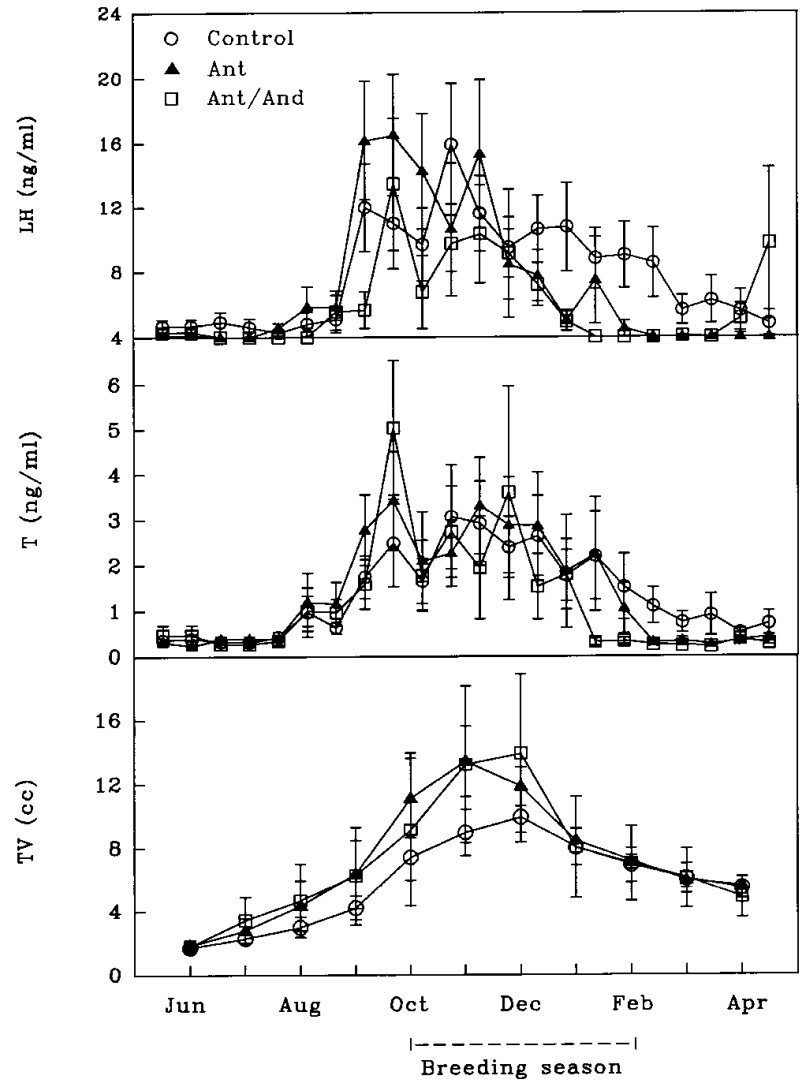

Figure 3 Serum LH (top) and testosterone (T, middle) concentrations and testicular volume (TV, bottom) during year 4 in control, antide (Ant)- and antide + androgen (Ant/And)-treated animals that became mature during that year. Values are mean \pm S.E.M.

than those of animals in which puberty was to be delayed $(5 \cdot 25 \pm 0 \cdot 16 \mathrm{~kg})$. Treatment had no effect on body weight during this period (data not shown).

Penile length was greater in antide + androgen-treated animals than in either controls or antide-treated animals from 8 to 30 months of age $(P=0 \cdot 007)$, but with the onset of the breeding season of year 4 , penile length in controls increased at a more rapid rate than in either of the treated groups (Fig. 4).

Sperm counts in ejaculates did not differ between controls $\left(230 \pm 50 \times 10^{6} / \mathrm{ml}\right)$, antide- $\left(310 \pm 117 \times 10^{6} /\right.$ $\mathrm{ml})$ and antide+androgen-treated $\left(316 \pm 145 \times 10^{6} / \mathrm{ml}\right)$ animals during year 4 .

\section{Effect of social rank on peripubertal endocrine and morphometric changes}

In addition to treatment, another strong predictor of when puberty occurred was matriline rank. At birth, matriline rank did not differ across groups (controls $=4 \cdot 3 \pm$ $0 \cdot 6$; antide $=4 \cdot 8 \pm 1 \cdot 0 ;$ antide + androgen $=4 \cdot 6 \pm 1 \cdot 1)$, but

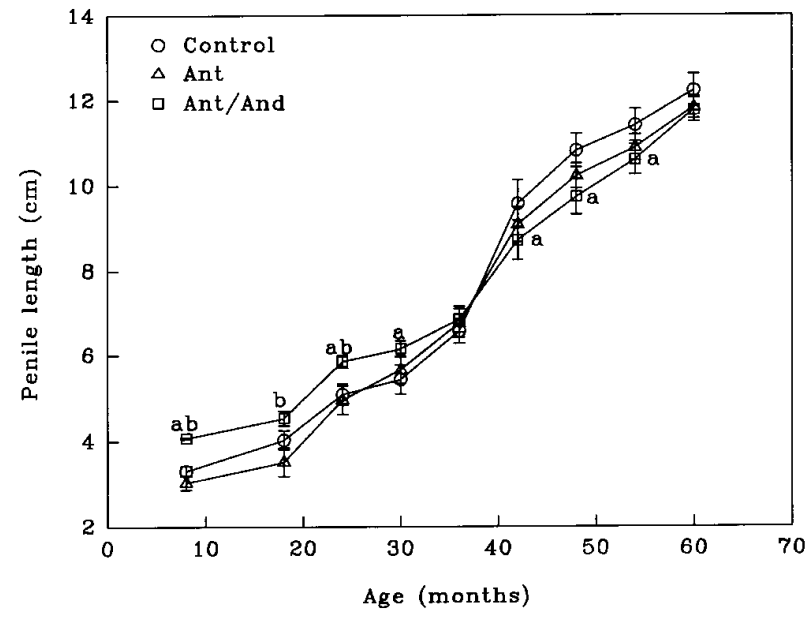

Figure 4 Penile length in control, antide (Ant)- and antide+ androgen (Ant/And)-treated animals. Values are mean \pm S.E.M. ${ }^{a}$ Significantly different from the corresponding control value; ${ }^{b}$ significantly different from the corresponding antide value.

during year 2, a social upheaval in the research group caused a fall in rank of the two highest matrilines, resulting in a marginally lower $(P=0.075$; controls $=3.6 \pm 0.4$; antide $=5 \cdot 6 \pm 0 \cdot 8 ; \quad$ antide + androgen $=6 \cdot 1 \pm 1 \cdot 1)$ social rank of treated subjects compared with controls. This became an issue, because those animals that reached puberty (mean rank $=3 \cdot 7 \pm 0 \cdot 6$ ) during year 4 came from higher ranked matrilines overall $(P=0.013)$ than those in which puberty was delayed (mean rank $=6 \cdot 8 \pm 0 \cdot 6$ ), although within each treatment group comparisons showed no significant effect of rank on puberty. For example, $78 \%$ of animals that attained sexual maturity came from the upper, compared with $22 \%$ from the lower, half of the social rank, whereas in those with delayed puberty, 33\% were high and $67 \%$ low ranking.

Rank was positively correlated with $\mathrm{LH}$ during October $(r=0.40, P=0.03$ and $r=0.45, P=0.01$ for the first and second blood sample respectively) and December $(r=0 \cdot 48$, $P=0.007$ and $r=0.44, P=0.02)$, with testosterone in October to December $(r=0.52, P=0.003$ and $r=0.48$, $P=0.008$ for December) and with testicular volume from August to March $(r=0 \cdot 57, P=0 \cdot 001$ for December) of year 4 (Fig. 5). There was no significant correlation between rank and body weight over this period.

\section{Discussion}

We reported previously that administration of a GnRH-A for the first 4 months of postnatal life either delayed or attenuated the peripubertal increase in LH and testosterone secretion, and testicular enlargement in male rhesus monkeys (Mann et al. 1989). In the male marmoset, treatment with a GnRH antagonist (the same one used 


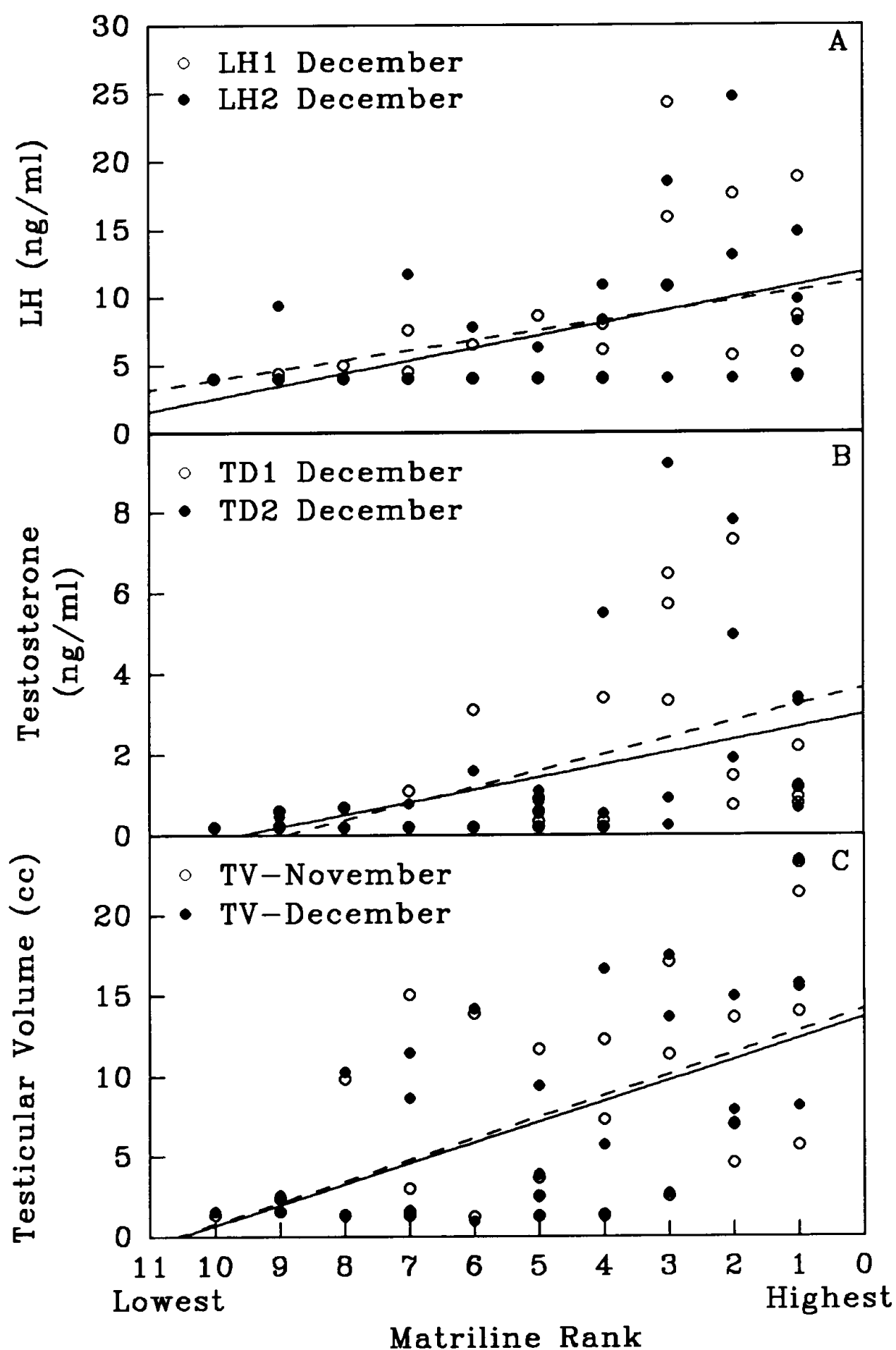

Figure 5 Representative data showing a correlation of LH concentration (top), testosterone concentration (middle) and testicular volume (bottom) with matriline rank during the breeding season of year 4 . The highest ranking family was assigned the lowest score in the matriline. Each data point represents a single value from one animal. The dotted line represents the best fit linear regression line for the open circles, and the solid line that for the closed circles. 
in the current study) from birth until 4 months of age, reduced the pubertal increase in serum $\mathrm{LH}$ and testosterone (Lunn et al. 1994). In the current study, neonatal treatment of male rhesus monkeys with antide was a significant predictor of whether puberty would be achieved during year 4 or delayed for another year. Eighty-three per cent of controls, compared with $44 \%$ of antide- or antide+androgen-treated animals became sexually mature during year 4 . Moreover, treatment also altered pubertal changes in testosterone secretion and testicular volume during year 4 . The age-related pattern of change in these two reproductive parameters during this period differed significantly between control and treated animals. Thus reversible suppression of the neonatal pituitary-testicular axis with antide altered the timing of the onset of puberty and pubertal endocrine events.

In the current study, social rank of the subject's family during years 3 and 4 had a major influence on the timing of puberty and magnitude of the pubertal increase in gonadotrophin and testosterone secretion, and testicular size. Of the animals (regardless of treatment) that achieved sexual maturity during their 4th year, $78 \%$ came from high ranking matrilines. Of those in which puberty was delayed, $67 \%$ were from low ranking matrilines. Moreover, mean serum LH and testosterone concentrations and testicular volume were positively correlated with matriline rank during the breeding season of year 4 . In female rhesus monkeys, higher ranking animals experienced first ovulation at an earlier age than lower ranking animals (Schwartz et al. 1985). The timing of the pubertal increase in testosterone secretion in adolescent male rhesus monkeys is influenced by the number of adult males in the social group (Rose et al. 1978). In another study, the highest ranking adolescent male rhesus monkeys had greater testosterone concentrations earlier in the breeding season of the 4th year of life, and values were increased for a longer period of time than in the lowest ranking animal (Bercovitch 1993). Testicular weight was also correlated with dominance rank in 4- and 5-year-old animals. In 3 -year-old male rhesus monkeys, serum testosterone, testicular weight, os penis growth and body weight maintenance during the breeding season were positively correlated with maternal rank (Dixson \& Nevison 1997). The results of the current study clearly confirm the importance of social rank as a major regulatory factor in determining the age at onset of puberty and the magnitude of peripubertal changes in reproductive indicators of sexual maturity in male rhesus monkeys. The neuroendocrine mechanisms that mediate the effect of social rank on sexual development of this species are not known.

Cortisol does not appear to mediate the effect of social rank on sexual maturation. Circulating cortisol concentrations were not inversely correlated with testosterone concentrations in adolescent or adult rhesus monkeys, and mean cortisol concentrations did not vary across rank (Bercovitch \& Clarke 1995). Concentrations of $\beta$-endorphin (a known inhibitor of GnRH secretion) in cerebrospinal fluid were not correlated with social rank, testosterone concentrations or genital development in adolescent male rhesus monkeys (Dixson \& Nevison 1997).

Although matriline rank was balanced across treatment groups at birth, rearrangement of social rank during year 2 resulted in a marginally lower rank of treated animals compared with controls during the peripubertal period. The exact magnitude of the potential confounding effect of social rank on the observed differences in the numbers of controls and treated animals reaching puberty during year 4 is impossible to assess fully.

Neonatal administration of high concentrations of androgen did not overcome the retarding effects of antide treatment, low social rank, or both, on sexual development in antide + androgen-treated animals. In antide+androgentreated animals, circulating concentrations of testosterone during the neonatal period were five to six times greater than those measured in control animals, and yet this group had the lowest number of animals achieve sexual maturity during the 4th year. Penile length, a marker for level of androgenization, was greater in antide + androgen-treated animals than in controls or antide-treated animals throughout the juvenile period, but the rate of sexual maturation was not normalized in these animals. This result at the very least suggests that administration of antide to infants may have effects on the maturation of the hypothalamicpituitary-testicular axis that are independent of its effect on testosterone suppression. In contrast, two additional antide-treated animals treated with androgen for 16 weeks rather than 6 weeks, and simultaneously with animals in the current study, showed signs of accelerated sexual maturation (Mann et al. 1995). This suggests that more prolonged exposure to androgen (testosterone concentrations were increased for more than 6 months in these animals) can reverse the effects of antide retardation of sexual maturation.

It appears from our work that several key regulatory factors are involved in determining the rate of sexual maturation and the timing of puberty in male rhesus monkeys. One of the important overriding factors appears to be the social rank of the adolescent. The majority of animals achieving sexual maturity during the breeding season of year 4 were from high ranking matrilines. Treatment was also a predictor of those animals that would reach puberty during year 4 . More control animals than treated animals were in this group. If puberty was not achieved in year 4 , then puberty was delayed until the subsequent breeding season. Peripubertal adolescent male rhesus monkeys, regardless of rank or treatment, do not become sexually mature during the non-breeding season, but the achievement of reproductive competence is confined to the autumn breeding season (Mann et al. 1989, 1993, and current study). Body weight or the achievement 
of a critical body mass may have a role in the process of sexual maturation, but may be subservient to the more critical factors of rank, treatment and season. As the onset of puberty in male primates is probably driven by the re-emergence of the GnRH pulse generator, and because activity of this generator is greatest during the breeding season, there probably exist neuroendocrine mechanisms that suppress the seasonal increase in the activity of this system in some animals (e.g. low ranking or animals treated neonatally with $\mathrm{GnRH}$ analogs), delaying the onset of puberty for one full year.

\section{Acknowledgements}

The GnRH antagonist analog used was synthesized at the Salk Institute under contract NO1-HD-02906 with the NIH, and made available by the Contraceptive Development Branch, Center for Population Research, NICHHD, who also provided the testosterone ester. The rhesus monkey pituitary reference preparation (WP-XV20) used in the LH bioassay was provided by the NIDDK and National Hormone and Pituitary Program. All experiments were performed according to the principles and procedures of the NIH Guidelines for the Care and Use of Laboratory Animals. The Yerkes Regional Primate Research Center is fully accredited by the American Association for the Accreditation of Laboratory Animals Care.

The study was supported by NIH grants HD26423, RR03034, RR00165 and K02-MH01062.

\section{References}

Baum MJ, Erskini MS, Kornberg E \& Weaver CE 1990 Prenatal and neonatal testosterone exposure interact to affect differentiation of sexual behavior and partner preference in female ferrets. Behavior Neuroscience 104 183-198.

Bercovitch FB 1993 Dominance rank and reproductive maturation in male rhesus macaques (Macaca mulatta). Journal of Reproduction and Fertility 99 113-120.

Bercovitch FB \& Clarke S 1995 Dominance rank, cortisol concentrations, and reproductive maturation in male rhesus macaques. Physiology and Behavior 58 215-221.

Dixson AF \& Nevison CM 1997 The socioendocrinology of adolescent development in male rhesus monkeys (Macaca mulatta). Hormones and Behavior 31 126-135.

van den Dungen HM, van Dieten JAMJ, van Rees GP \& Schoemaker J 1990 Testicular weight, tubular diameter and number of Sertoli cells in rats are decreased after early prepubertal administration of an LHRH-antagonist; the quality of spermatozoa is not impaired. Life Sciences 46 1081-1089.

Eisler JA, Tannenbaum PL, Mann DR \& Wallen K 1993 Neonata testicular suppression with a GnRH agonist in rhesus monkeys: effects on adult endocrine function and behavior. Hormones and Behavior 27 551-567.

Filicori M \& Flamigni C 1988 GnRH agonists and antagonists current clinical status. Drugs 35 63-82.

Forest MG 1990 In Control of the Onset of Puberty, pp 451-477. Eds MM Grumbach, PC Sizonenko \& ML Auberrt. Baltimore: William \& Wilkins.
Friedman AJ 1990 The biochemistry, physiology, and pharmacology of gonadotropin releasing hormone $(\mathrm{GnRH})$ and $\mathrm{GnRH}$ analogs. In Gonadotropin Releasing Hormone Analogs Applications in Gynecology, pp 1-15. Eds RL Barbieri, AJ Friedmann. New York: Elsevier.

Gould KG, Warner H \& Martin DE 1978 Rectal probe electroejaculation of primates. Journal of Medical Primatology 7 213-221.

Goy RW \& McEwen BS 1980 Sexual Differentiation of the Brain, pp 1-12, 44-54, 83-114. Cambridge: MIT Press.

Huhtaniemi I, Nevo N, Amsterdam A \& Naor Z 1986 Effect of postnatal treatment with a gonadotropin-releasing hormone antagonist on sexual maturation of male rats. Biology of Reproduction 35 501-507.

Huhtaniemi I, Pakarienen P, Sokko T \& Kolho K-L 1989 Pituitarygonadal function in the fetus and neonate. In Control of the Onset of Puberty, edn 3, pp 101-109. Eds D van de Waal, GP Rees \& J Schoemaker. Amsterdam: Excerpta Media.

Kolho K-L \& Huhtaniemi I 1989 Neonatal treatment of male rats with a gonadotropin-releasing hormone antagonist impairs ejaculation and fertility. Physiology \& Behavior 46 373-377.

Lunn SF, Recio R, Morris K \& Fraser HM 1994 Blockade of the neonatal rise in testosterone by a gonadotropin-releasing hormone antagonist: effects on timing of puberty and sexual behavior in the male marmoset monkey. Journal of Endocrinology 141 439-447.

Mann DR \& Fraser HM 1996 The neonatal period: a critical interval in male primate development (Commentary). Journal of Endocrinology 149 191-197.

Mann DR, Davis-DaSilva M, Wallen K, Coan P, Evans DE \& Collins DC 1984 Blockade of neonatal activation of the pituitary-testicular axis with continuous administration of a gonadotropin-releasing hormone agonist in male rhesus monkeys. Journal of Clinical Endocrinology and Metabolism 58 262-267.

Mann DR, Smith MM, Gould KG \& Collins DC 1985 Effects of a gonadotropin-releasing hormone agonist on luteinizing hormone and testosterone secretion and testicular histology in male rhesus monkeys, Macaca fascicularis. Fertility and Sterility $\mathbf{4 3}$ $115-121$.

Mann DR, Gould KG, Collins DC \& Wallen K 1989 Blockade of neonatal activation of the pituitary-testicular axis: effect on peripubertal luteinizing hormone and testosterone secretion and on testicular development in male monkeys. Journal of Clinical Endocrinology and Metabolism 68 600-607.

Mann DR, Akinbami MA, Gould KG, Tanner JM \& Wallen K 1993 Neonatal treatment of male monkeys with a gonadotropin-releasing hormone agonist alters differentiation of central nervous system centers that regulate sexual and skeletal development. Journal of Clinical Endocrinology and Metabolism 76 1319-1324.

Mann DR, Ansari AA, Akinbami MA, Wallen K, Gould KG \& McClure HM 1994 Neonatal treatment with luteinizing hormonereleasing hormone analogs alters peripheral lymphocyte subsets and cellular and humorally mediated immune responses in juvenile and adult male monkeys. Journal of Clinical Endocrinology and Metabolism 78 292-298.

Mann DR, Akinbami MA, Gould KG \& Wallen K 1995 Sexual development: importance of neonatal testosterone. Biology of Reproduction 52 (Suppl 1) 91.

Plant TM 1994 Puberty in primates. In The Physiology of Reproduction, edn 2, pp 453-485. Eds E Knobil \& JD Neill. New York: Raven Press Ltd

Rose RM, Bernstein IS, Gordon TP \& Lindsley JG 1978 Changes in testosterone and behavior during adolescence in the male rhesus monkey. Psychosomatic Medicine 40 60-70.

Sade DS 1967 Determinants of dominance in a group of free ranging rhesus monkeys. In Social Communications Among Primates. Eds SA Altman, pp 99-114. Chicago: University of Chicago Press. 
Schwartz SM, Wilson ME, Walker ML \& Collins DC 1985 Social and growth correlates of puberty onset in female rhesus monkeys. Nutrition and Behavior 2 225-232.

Sharpe RM 1993 Declining sperm counts in men - is there an endocrine cause? (Commentary.) Journal of Endocrinology and Metabolism 136 357-360.

Sharpe RM 1994 Could environmental, oestrogenic chemicals be responsible for some disorders of human male reproductive development? Current Opinion in Urology 4 295-301.
Steiner R, \& Brenmer WJ 1981 Endocrine correlates of sexual development in the male monkey, Macaca fascicularis. Endocrinology 109 914-919.

Wallen K, Aestripieri D \& Mann DR 1995 Effects of neonatal testicular suppression with a GnRH antagonist on social behavior in groupliving juvenile rhesus monkeys. Hormones and Behavior 29 322-337.

Received 9 June 1997

Accepted 1 October 1997 